\title{
Mild Colon Dysplasia
}

National Cancer Institute

\section{Source}

National Cancer Institute. Mild Colon Dysplasia. NCI Thesaurus. Code C4848.

A morphologic finding indicating the presence of mild dysplastic cellular changes and mild architectural changes in the glandular epithelium of the colonic mucosa. There is no evidence of invasion. 